\title{
The Effect of Formalin Addition on the Electrical Impedance of White Shrimp
}

\author{
Sri Herwiningsih, Chomsin S. Widodo, Fahrizal Rifqi
}

\begin{abstract}
Shrimp is one of the important protein sources for diet. Shrimp has high water content, causing quick spoilage of the product and degradation of its quality from post-harvesting to end-consumers. The use of formalin to prolong the shelf life of shrimp has become a raised issue in the food safety field as formalin could have negative impacts on human health. Therefore, its use in food products is prohibited. The electrical impedance spectroscopy could be used to detect the food additives such as formalin in shrimp. This paper discusses the impedance of the shrimp after soaked in formalin solution. The shrimp samples were soaked in the different concentrations of formalin solution and stored for five days. The shrimp without formalin was used as a control sample. The electrical properties of the shrimp samples were measured using the electrical impedance spectroscopy method using frequency from $1 \mathrm{~Hz}$ to $1 \mathrm{MHz}$ each day. The results show that the impedance of the shrimp decrease with an increase of the storage time. The shrimp with formalin experience a slower degradation compared to the shrimp without formalin. Higher the formalin concentrations $(10 \%-40 \%)$ added to the shrimp causes a slower texture change on the shrimp compared to lower formation concentrations (1\%-5\%). The impedance of the shrimp decrease with the increase of injected signal frequency. The electrical impedance spectroscopy has the potential to be developed as a tool in food safety field to detect food additives contained in the food to ensure the safety of the food products to the consumers.
\end{abstract}

Keywords: Electrical impedance spectroscopy, formalin, shrimp.

\section{INTRODUCTION}

Shrimp is one of the fisheries and marine products, which is a good source of protein besides fish and meat. Shrimp has a high protein content (almost $90 \%$ from its dry weight) and low lipid content, which are beneficial for diet. Shrimp is also rich in essential amino acids (leucine, lysine, and phenylalanine), macro minerals (calcium, magnesium, phosphor, potassium, and sodium), micro minerals (copper, iron, manganese, selenium, and zinc), and vitamins (A, D, E, $\mathrm{B}_{3}$, and $\mathrm{B}_{12}$ ). Shrimp is an important anti-inflammatory agent

\section{Revised Manuscript Received on November 05, 2020.}

* Correspondence Author

Sri Herwiningsih*, Physics Department, Universitas Brawijaya, Malang, Indonesia. Email: herwin@ub.ac.id.

Chomsin S. Widodo, Physics Department, Universitas Brawijaya, Malang, Indonesia. Email: chomsin@ub.ac.id.

Fahrizal Rifqi, Physics Department, Universitas Brawijaya, Malang, Indonesia.

(C) The Authors. Published by Blue Eyes Intelligence Engineering and Sciences Publication (BEIESP). This is an open access article under the CC BY-NC-ND license (http://creativecommons.org/licenses/by-nc-nd/4.0/) due to its high selenium and docosahexaenoic acid content, as well as low saturated fat. Shrimp also beneficial for cardiac as it has a low value of atherogenic and thrombogenic compared to other non-vegetarian foods. Besides that, shrimp is an essential antioxidant source due to its astaxanthin active compound content [1, 2].

The water content in shrimps was up to $75 \%$ per shrimps weight [1]. As other fisheries product, the high water content causing the shrimps getting rotten quickly and decrease its quality since post-harvesting until reach end-consumers [3]. The factors affecting a decrease in shrimp quality are the effect of environmental changes from its original habitat to a new environment, high content of humidity in shrimp body, microbial activities in guts, damage during handling, and microbial infection during post-harvest handling. This damage appears in the form of changing the odour, colour, texture, shape, and composition [3].

Post-harvesting handling, storage and processing also cause protein change in the shrimp. The length of storage time or high temperature could increase the degradation of myosin and actin chains. Many preservation efforts have been made to maintain shrimp quality. Degradation of these proteins causes an increase in protein solubility during washing. The use of ice cube during shrimp storage is one of the strategies to maintain shrimp quality [3].

Besides preservation using the ice cubes, it has been reported the use of formalin in food [4], including in fisheries products $[5,6]$. Formalin is a $40 \%$ formaldehyde solution in water, commonly used for specimen preservation [7]. Formalin has negative impacts on human health, such as causing damage to the liver and kidney, acidosis, depression of the central nervous system, and ulcer in gastrointestinal [7]. Therefore, formalin is not recommended to be used in foods.

The formalin content in food could be detected using chemical reagents [4] and high-performance liquid chromatography (HPLC) analysis [6]. Besides those methods, detection of food additives could be performed using electrical impedance spectroscopy (EIS) method [8]. This method evaluates the electrical properties of biological materials by employing a signal within a specific frequency range to measure electrical impedances of the materials. The resulted spectra are then analyzed using an equivalent electrical circuit [9]. The EIS method enables the detection of impurities in food, opening further development in the food safety field. Several studies have used the EIS method to analyze the electrical impedance of trout fish [10], the acidity level of citrus juice [11], food additives [9], and quality of fish and meat [12].

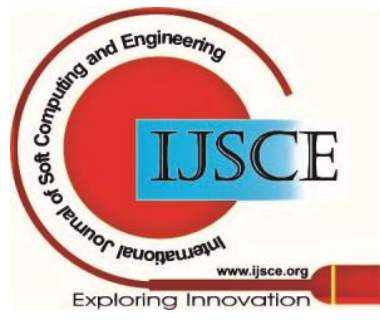




\section{The Effect of Formalin Addition on the Electrical Impedance of White Shrimp}

This paper presents a work in analyzing the impedance of the shrimps, soaking in the formalin solution with varied concentrations using the EIS method.

\section{MATERIALS AND METHODS}

This work was divided into several steps. The first step was preparation of formalin solution with different concentrations. The second step was soaking process of the shrimp samples in the formalin solutions. The last step was the measurement of the electrical impedance of the shrimp sample using the electrical impedance spectroscopy method.

\section{A. Sample Preparation}

This study used white shrimps (Litopenaueous vannamei) soaked in the varied concentration of formalin solution. A $37 \%$ formalin solution was used to prepare $200 \mathrm{ml}$ of formalin solution with concentrations of $1 \%, 2 \%, 3 \%, 4 \%, 5 \%, 10 \%$, $20 \%, 30 \%$ and $40 \%$. The amount of the $37 \%$ formalin solution required was determined using equation 1 .

$$
M_{1} V_{1}=M_{2} V_{2}
$$

$\mathrm{M}_{1}=$ concentration of the $37 \%$ formalin solution (\%)

$\mathrm{V}_{1}=$ volume of the $37 \%$ formalin solution $(\mathrm{mL})$

$\mathrm{M}_{2}=$ desired concentration (\%)

$\mathrm{V}_{2}=$ volume of desired solution (mL)

After measuring its weight and length, the shrimp were soaked in the different concentrations of the formalin solution for two hours. A $0 \%$ formalin solution (only pure water) was used as a control. The samples were then drained for three minutes to remove excess water from the shrimp body.

The treated samples were then put at room temperature for five days, aiming to evaluate the effect of the storage time on the impedance value of the shrimp with the formalin and the shrimp without the formalin. The impedance measurement was performed in each day from day one to day five.

\section{B. Measurement of Electrical impedance}

The impedance measurement was performed using the Picoscope S5000 type 5422B. This instrument was equipped with an AC signal generator, producing signals with a broad frequency, ranging from $1 \mathrm{~Hz}$ to $20 \mathrm{MHz}$. The signal generator produced 1 Volt voltage. The amplitude and frequency of the signal could be adjusted using a Personal Computer (PC) connected to the Picoscope.

The voltage produced by the signal generator was converted into the current by the $\mathrm{V}$ to I converter. The electrical current of $1 \mu \mathrm{A}$ was injected into the sample through the probes, consisting of four needle electrodes. The Picoscope has two channels: channel 1 displayed the input voltage, while channel 2 displayed the output voltage from the measurement of the needle electrodes. The measurement setting is showed in Fig. 1.

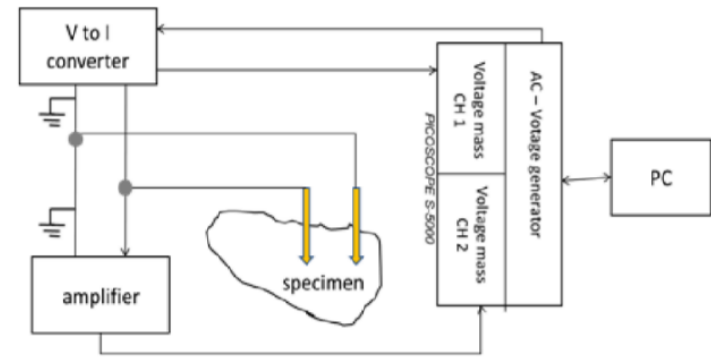

Fig. 1. The measurement setting of the electrical impedance [10].

The needle electrodes were made of silver, having a diameter of $0.7 \mathrm{~mm}$ and a length of $15 \mathrm{~mm}$. The distance between needle electrodes was $0.5 \mathrm{~cm}$, while the distance between the first and the second probes was $1.32 \mathrm{~cm}$. The impedance measurement was performed using the frequencies from $1 \mathrm{~Hz}$ to $1 \mathrm{MHz}$.

\section{Data analysis}

The results of the measurement were the voltage of each measured sample. The measured output voltage was peak-to-peak voltage $\left(\mathrm{V}_{\mathrm{pp}}\right)$. Therefore, the voltage could be calculated by dividing the Vpp by factor of 2 as shown in Equation 2.

$$
V=V_{p p} / 2
$$

The impedance of the sample was determined using Equation 3.

$$
Z=V / I
$$

$\mathrm{Z}=$ Electrical impedance $(\mathrm{Ohm})$

$\mathrm{V}=$ Voltage $($ Volt $)$

$\mathrm{I}=$ Injected current (Ampere)

The electrical impedance was plotted with the frequency to evaluate the characteristics of the electrical impedance in each sample.

\section{RESULTS AND DISCUSSION}

\section{A. The electrical impedance of the shrimps}

Fig. 2 shows the electrical impedance of the shrimps without formalin. Higher the frequency causes a lower impedance. The impedance value of the shrimps also decreases with an increase in the storage time.

Texture changes were observed in the shrimp without formalin on day 2. It was also found that on day 2 the maggots were found in the shrimp. On day 5, the shrimp has become rotten, changing its color into blackish-brown color and producing a strong unpleasant odor.

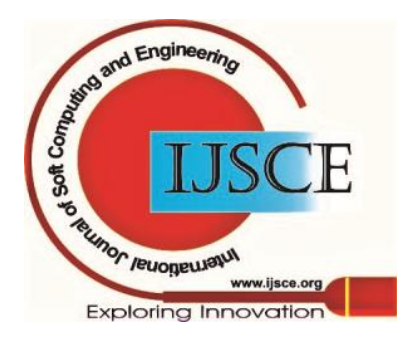




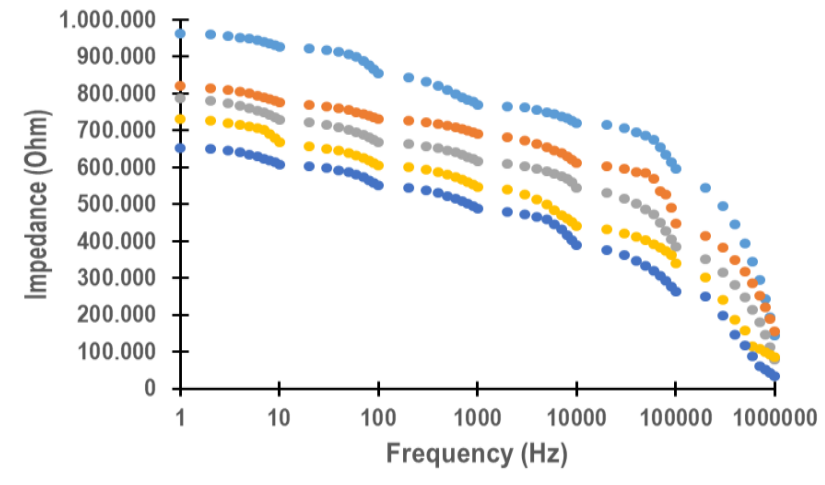

Fig. 2. The impedance of the shrimp without formalin from day one to day five.

The addition of formalin solution with the concentrations of $1 \%-5 \%$ results in the impedance value shown in Fig. 3a (day 1) and 3b (day 5).

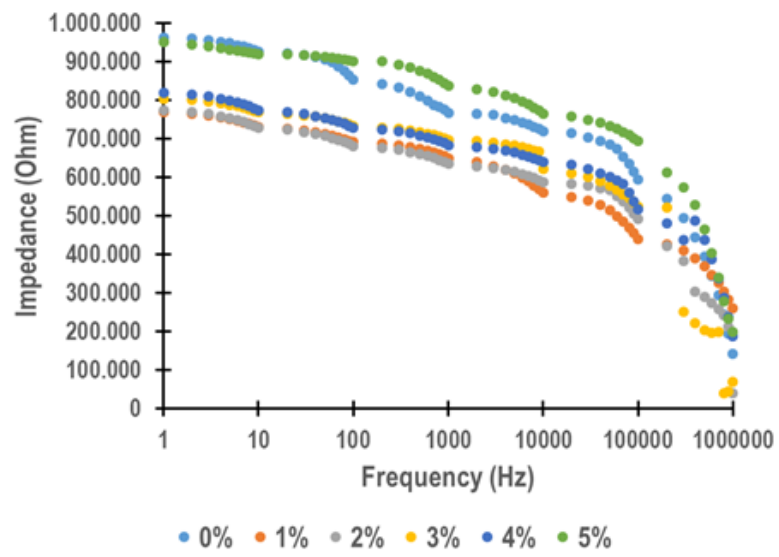

(a)

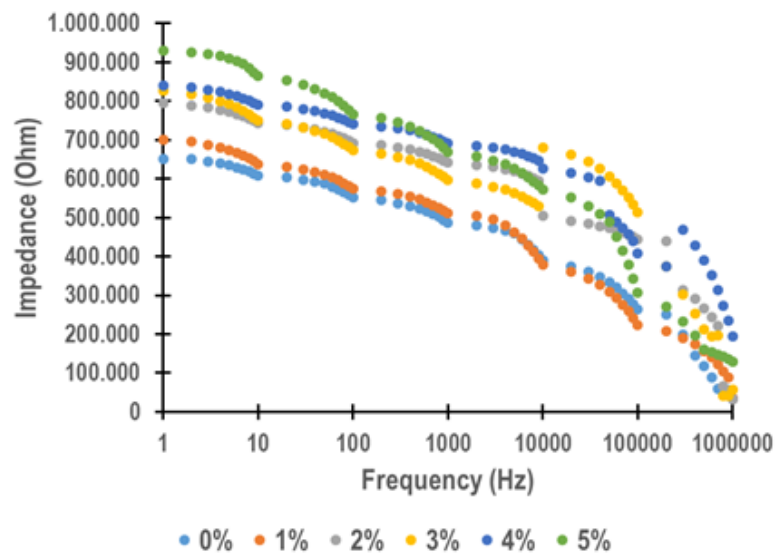

(b) formalin $1 \%$ to $5 \%$ on a) day 1 and b) day 5

On day 1 , the shrimp with formalin $5 \%$ has the impedance value close to the impedance of the shrimp without formalin. The shrimp impedance decreases for the shrimp with formalin concentrations of $1 \%-4 \%$. The effect of giving formalin observed on day 5 , where the impedance of the shrimp with formalin is higher compared to the impedance of the shrimp without formalin. Lower the formalin concentration causes a lower measured electrical impedance of the shrimp.

The shrimp soaked in formalin solution experience a slower texture change compared to the shrimp without
Fig. 3. The impedance value of the shrimps with

formalin. Higher the concentration of the formalin solution causes slower changes in the shrimp texture. For example, the shrimp soaked in formalin 5\% its texture change on day 5 .

The impedance values of the shrimp soaked in formalin solution with higher concentrations (10\% - 40\%) are showed in Fig. 4a (day 1) and Fig. 4b (day 5).

On day 1 , the electrical impedance of the shrimp without formalin is relatively similar to the electrical impedance of the shrimp with formalin. At frequency above $100 \mathrm{~Hz}$, there is the dispersion of the electrical impedance of the shrimp with formalin.

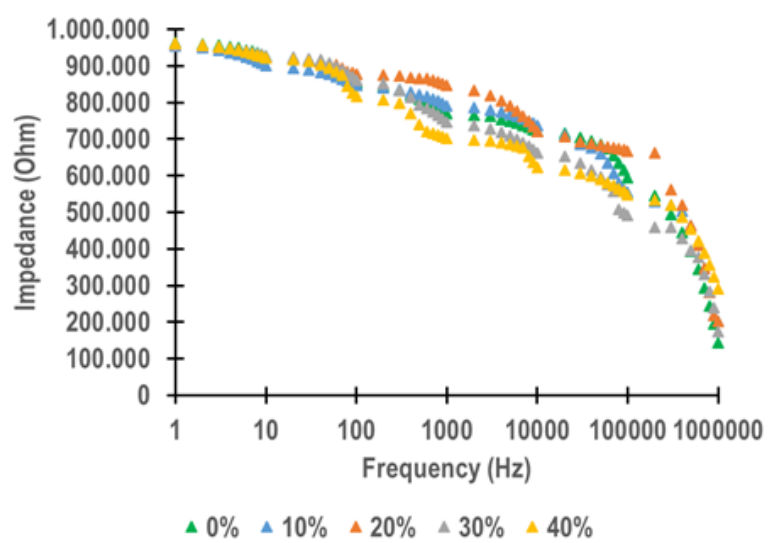

(a)

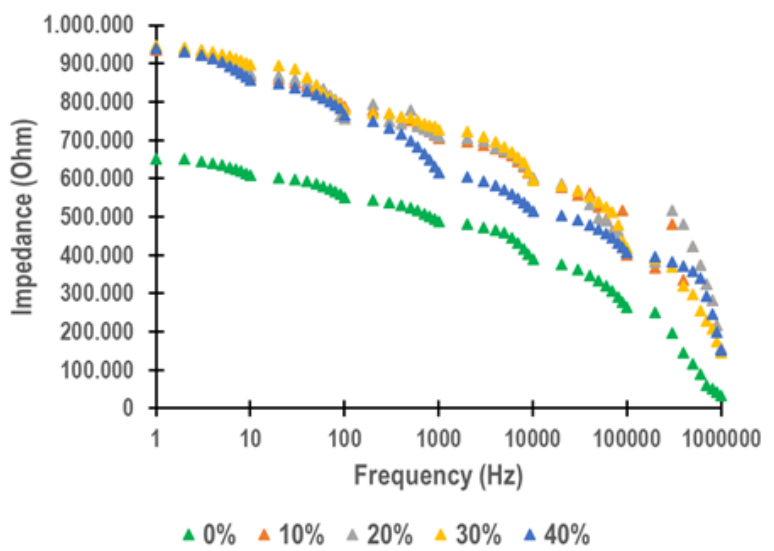

(b)

Fig. 4. The impedance of the shrimp with formalin concentration of $10 \%-40 \%$, a) on day 1, b) on day 5 .

On day 5 , there is a difference between the electrical impedance of the shrimp without formalin and the shrimp with high formalin concentrations (10\% - 40\%). The shrimp without formalin has a lower electrical impedance compared to the shrimp with formalin. The reason is the shrimp without formation has become rotten on day 5 , while the shrimp with high formalin concentrations has not become rotten until day 5. The texture of the shrimp with high formalin concentrations does not change until day 4 . The added formalin could inhibit the microbial growth causing rotting in the shrimp [14]. Table-I presents the impedance of the shrimp on day 5 from different formalin concentrations for the selected frequencies.

Published By:

Blue Eyes Intelligence Engineering and Sciences Publication 


\section{The Effect of Formalin Addition on the Electrical Impedance of White Shrimp}

Table- I: The impedance of the shrimp on day 5 from different formalin concentrations

\begin{tabular}{|l|c|c|c|c|c|}
\hline $\begin{array}{c}\text { Frequency } \\
(\mathbf{H z})\end{array}$ & \multicolumn{5}{|c|}{$\begin{array}{c}\text { Impedance of the shrimp on day } 5 \text { from different } \\
\text { formalin concentrations (kOhm) }\end{array}$} \\
\hline & $0 \%$ & $1 \%$ & $5 \%$ & $20 \%$ & $40 \%$ \\
\hline 1 & 651.67 & 700.32 & 930.91 & 941.16 & 940.55 \\
\hline 10 & 608.29 & 638.67 & 864.14 & 876.16 & 856.74 \\
\hline 100 & 551.51 & 574.93 & 766.77 & 756.00 & 765.56 \\
\hline 1000 & 487.41 & 511.19 & 669.40 & 710.50 & 615.54 \\
\hline 10000 & 389.29 & 377.83 & 572.03 & 602.00 & 513.85 \\
\hline 100000 & 263.96 & 224.56 & 306.44 & 410.00 & 407.71 \\
\hline 1000000 & 33.77 & 33.76 & 128.93 & 157.00 & 152.53 \\
\hline
\end{tabular}

\section{B. The relationship between impedance and frequency}

It is shown in Fig. 2 to Fig.4 that the impedance value of the shrimp decrease with the increase of given signal frequencies.

The decrease in the impedance is caused by the presence of capacitance effects of the cell membrane in the shrimp tissues, which acts as barrier between intracellular fluids and extracellular fluids. Both of these fluids are rich in ions. Extracellular fluids are rich in $\mathrm{Na}^{+}$and $\mathrm{Cl}^{-}$ions, while intracellular fluids are rich in $\mathrm{K}^{+}$ion and anion from protein and phosphates [13,14]. Intracellular and extracellular fluids act as conductors modeled as $\mathrm{R}_{\mathrm{i}}$ and $\mathrm{R}_{\mathrm{e}}$, while cell membrane act as a capacitor modelled as $C_{m}$ [14]. The cell membrane is selectively permeable to certain compounds. The lipid bilayer components of the membrane do not permeable to the charged ions, showing capacitive properties. The presence of the membrane protein, which has a function as the channel for ions transport in and out of the cell, causing the membrane has resistive properties. The value of $R_{i}, R_{e}$, and $C_{m}$ parameters depend on the ion content within the cells and their mobility during the metabolism process [14]. When the injected current has a low frequency, the shrimp body show resistive properties. This is because the current flows only outside the cells. Therefore, the measured impedance is high. As the injected current increases, the ion mobility within the tissue increases, causing the conductivity within the tissue also increases. Therefore, the value of the measured impedance is low. At high frequency, the electrical current flows both in the extracellular fluids and intracellular fluids because it penetrates the cell membrane. Therefore, the capacitance of the membrane could not be neglected at high frequency [8]. When the injected current has a very high frequency, the impedance value is getting very low. A dramatic decrease in the impedance value is observed for the injected current with the frequency above $100 \mathrm{kHz}$. The decrease in the electrical impedance of the shrimp at specific frequency range could be explained using the Schwan dispersion theory. The impedance dispersion observed at a few $\mathrm{Hz}$ to $\mathrm{kHz}$ is called alpha dispersion, which appears due to the polarization phenomenon in the lipid bilayer. The impedance dispersion at the frequency range from $\mathrm{kHz}$ to $\mathrm{MHz}$ is called beta dispersion, which appears due to the polarization of the interface in the system. The beta dispersion is related to the dielectric properties of the membrane cell and its interaction with the extracellular fluids or intracellular fluids [13].

\section{The relationship between impedance and storage time}

As the storing time increases, the impedance of the shrimp decreases. The longer the storage time might increase the possibility of cell membrane damage and causes changes in the extracellular and intracellular fluids [13]. The changes in the cellular properties affect the electrical properties of the shrimp. The length of the storage time affects meat quality. The longer the storage time decreases the meat quality due to the decrease of the protein function within the meat. As the results of the protein damage, the concentration of ion $\mathrm{Na}^{+}, \mathrm{K}^{+}$ and $\mathrm{Cl}^{-}$in the extracellular and intracellular fluids increases. Consequently, the electrical conductivity within the tissue also increases. Therefore, the measured impedance of the tissue is getting lower. The decrease of the impedance is also affected by the presence of microbes in the shrimp body. As the amount of the microbes increase, the measured impedance is getting lower. This phenomenon was observed on day 5 , where the shrimp has become rotten. Formalin addition with high concentrations could prevent the presence of the microbes in the shrimps. Therefore, the shrimps has a longer shelf life. Since formalin bind with protein, the protein could not be damaged by the bacteria [14]. This phenomenon was observed at the impedance of the shrimp soaked in the formalin solution with the concentration of $40 \%$. The impedance of the shrimp for the formalin concentration of $40 \%$ is higher compared to the impedance of the shrimp soaked in the lower concentrations of the formalin solution.

This study shows that the EIS method can demonstrate the difference in the impedance value between the shrimp with formalin and the shrimp without formalin. Future works could explore further the potential of the EIS method to be used as one tool to detect the presence of food additives, which may endanger the consumers besides the chemical analysis method.

\section{CONCLUSION}

Formalin addition to the shrimp affect the electrical impedances of the shrimp. Higher the formalin concentrations results in a higher impedance compared to lower concentrations especially after five days of the storage time. The addition of high formalin concentrations causes a slower texture change of the shrimp. The impedance is also affected by the storage time. The impedance tends to decreases with the increase in the storage time, especially for the shrimp without formalin. The frequency of the injected current also affect the measured impedance. The impedance tends to decrease when the frequency of injected current increases. The EIS method could be further developed as a tool in food safety to ensure that food product received by the consumers are free from toxic compounds.

\section{ACKNOWLEDGMENT}

Author would like to thank all parties that have helped in finishing the research.

\section{REFERENCES}

1. J. S. Dayal, A. G. Ponniah, H. I. Khan, et al. (2013). Shrimps nutritional perspective. Curr Sci. 104:1487-1491.

2. J. Ngginak, H. Semangun, J. C. Mangimbulude, F. S. Rondonuwu. (2013). Active compounds in shrimp and its application in food. J Sains Med. 5:128-145. (In Indonesian).

Published By:

Blue Eyes Intelligence Engineering and Sciences Publication

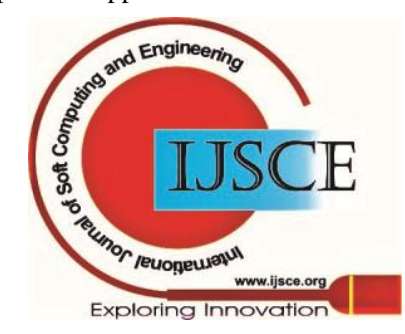


3. M. S. Rahman, Handbook of Food Preservation. Third Edition. Boca Raton: CRC Press, 2020.

4. F. Faradila, Y. Alioes, E. Syamsir. (2014). Identification of formalin in meat ball sold in Padang City. J Kesehat Andalas. 3:156-158. https://doi.org/10.25077/jka.v3i2.71. (In Indonesian)

5. R. Uddin, M. I. Wahid, T. Jesmeen, et al. (2011). Detection of formalin in fish samples collected from Dhaka city, Bangladesh. Stamford $J$ Pharm Sci. 4:49-52. https://doi.org/10.3329/sjps.v4i1.8866

6. S. Bhowmik, M. Begum, M. A. Hossain, et al. (2017). Determination of formaldehyde in wet marketed fish by HPLC analysis: A negligible concern for fish and food safety in Bangladesh. Egypt J Aquat Res. 43:245-248. https://doi.org/10.1016/j.ejar.2017.08.001

7. C. K. Pandey. (2000). Toxicity of ingested formalin and its management. Hum Exp Toxicol. 19:360-366 https://doi.org/10.1191/096032700678815954

8. M. Grossi, B. Riccò. (2017). Electrical impedance spectroscopy (EIS) for biological analysis and food characterization: A review. J Sensors Sens Syst. 6:303-325. https://doi.org/10.5194/jsss-6-303-2017

9. A. Nakonieczna, B. Paszkowski, A. Wilczek, et al. (2016). Electrical impedance measurements for detecting artificial chemical additives in liquid food products. Food Control. 66:116-129. https://doi.org/10.1016/j.foodcont.2016.01.044

10. R. R. A. Putri, C. Sulistya, D. R. Santoso. (2017). Analysis of the electrical impedance of Trout fish meat stored in the freezer. Indones $J$ Appl Phys. 6:117-124. https://doi.org/10.13057/ijap.v6i02.1780. (In Indonesian)

11. J. Juansah, I. W. Budiastra, K. Dahlan. (2012). The Prospect of Electrical Impedance Spectroscopy as Non-Destructive Evaluation of Citrus Fruit Acidity. Int J Emerg Technol Adv Eng .2:58-64.

12. A. Fuentes, R. Masot, I. Fernández-Segovia, et al. (2013). Differentiation between fresh and frozen-thawed sea bream (Sparus aurata) using impedance spectroscopy techniques. Innov Food Sci $\begin{array}{llll}\text { Emerg } & \text { Technol. } & 19: 210 & \text { - }\end{array}$ https://doi.org/10.1016/j.ifset.2013.05.001

13. O. Hermawan, A. T. Mukti, M. Yasin. (2020). Formaldehydecontent in white shrimp after formalin soaking with different doses. J Aquac Fish Heal. 9:69-74. https://doi.org/10.20473/jafh.v9i1.15915

14. X. Zhao, H. Zhuang, S. C. Yoon, et al. (2017). Electrical impedance spectroscopy for quality assessment of meat and fish: A review on basic principles measurement methods, and recent advances. J. Food Qual.1-16.

\section{AUTHORS PROFILE}

Sri Herwiningsih BSc (Physics), M.App.Sc (Medica Physics), Ph.D (Physics), her research interest is in Biophysics and Medical Physics fields. She works in computation for radiotherapy fields, especially related with Monte Carlo modelling of the external beam radiotherapy treatments.

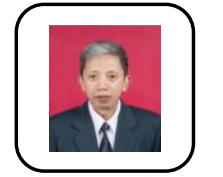

Chomsin S. Widodo Ph.D (Physics) his research interest is in Bioelectricy and Biophysics fields. His research focuses on exploring the potential of electrical impedance spectroscopy methods in detecting any impurities and additives compounds in food. He also works on diagnostic radiology.

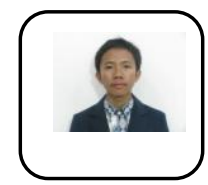

Fahrizal Rifqi B.Sc (Physics) his research interest is in the Biophysics field.

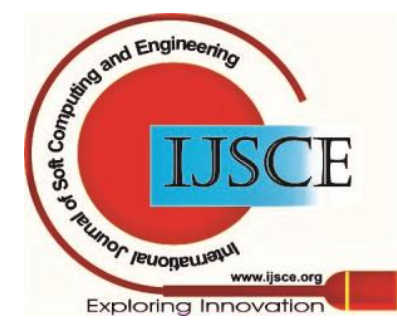

